Document downloaded from:

http://hdl.handle.net/10251/142681

This paper must be cited as:

Vimos-Lojano, D.; Martinez-Capel, F.; Hampel, H.; Vázquez, RF. (01-2). Hydrological influences on aquatic communities at the mesohabitat scale in high Andean streams of southern Ecuador. Ecohydrology. 12(1):1-17. https://doi.org/10.1002/eco.2033

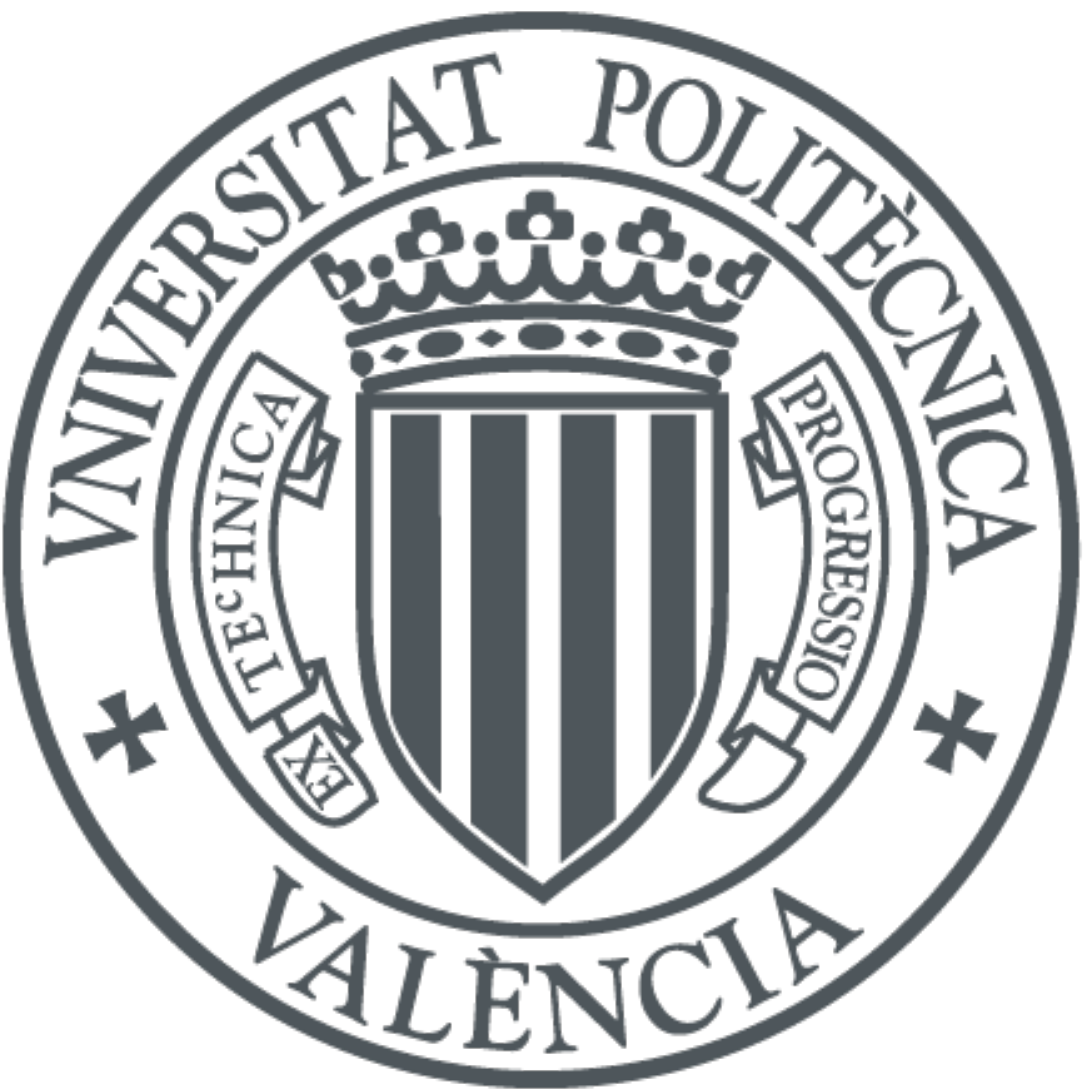

The final publication is available at

https://doi.org/10.1002/eco.2033

Copyright John Wiley \& Sons

Additional Information 


\title{
Hydrological influences on aquatic communities at the mesohabitat scale in high Andean streams of southern Ecuador
}

\author{
Vimos-Lojano, D.J. 1,2, Martínez-Capel, F. ${ }^{2}$, Hampel, H.,1, Vázquez, R.F.4,1 \\ ${ }^{1}$ Laboratorio de Ecología Acuática (LEA), Departamento de Recursos Hídricos y Ciencias \\ Ambientales, Universidad de Cuenca (UC), Av. 12 de Abril S/N, Cuenca, Ecuador. \\ ${ }^{2}$ Research Institute for Integrated Management of Coastal Areas (IGIC), Universitat Politècnica \\ de València, Grao de Gandia, Spain.
}

${ }^{3}$ Facultad de Ciencias Químicas, UC, Ecuador.

${ }^{4}$ Facultad de Ingeniería, UC, Ecuador.

Corresponding author: Diego Vimos-Lojano, Universidad de Cuenca, Departamento de Recursos Hídricos y Ciencias Ambientales, Universidad de Cuenca, Av. 12 de Abril S/N, Cuenca, Ecuador. Tel.: + 59374051000 ext. 2389 or 4493 or 4496.

Email: diego.vimos.1@gmail.com

Running Head: Hydrological influences on high Andean communities 


\begin{abstract}
This study assessed the effects of hydrological events on aquatic communities at the mesohabitat scale (pool, run and riffle) in the high Andean region. Four headwater sites in the Zhurucay microcatchment (southern Ecuador), with elevations higher than 3,500 m, were selected and monitored considering in each site a 50-m-long reach, and within each reach five cross-sections. In each of these reaches 19 sampling campaigns were conducted in the period December 2011 October 2013, collecting macroinvertebrates and physical characteristics. A total of 27 hydrological indices were calculated using the daily flow rate as input. Large Peak flow (LPF), Small Peak flow (SPF), and Low flow (LF) events were defined based on discharge thresholds. Multivariate statistics showed that 15 hydrological indices were significantly related to the aquatic community. Further, the study revealed that (i) peak events produced stronger effects on communities than LF events; (ii) the observed effects of LF events were weaker than those encountered in other latitudes; and (iii) local benthic communities have more resilience than similar communities studied in other latitudes.
\end{abstract}

Keywords: Ecohydrology, Andean streams, hydrological indices, mesohabitat, macroinvertebrates, ecological responses 


\section{INTRODUCTION}

The influence of hydrological factors on benthic macroinvertebrate communities received increasing attention in the last decade (Chang et al., 2008; Belmar et al., 2012; Mesa, 2012). Several studies have shown that the prior hydrological flow conditions affect the temporality of habitats and the distribution of aquatic flora and fauna (Poff et al., 1997; Kennen et al., 2010; Rolls et al., 2012). Further, it is known that changes caused by variations in discharge result in periodic interruptions in the stable conditions of the habitats used by species and that when stable flow conditions return, new habitats are created that are then colonised and repopulated by the biota (Lake, 2003). Commonly, the influence of hydrological variability is analysed using hydrological indices and the physical characteristics of the riverbed, which are then associated with the macroinvertebrate communities (Lancaster and Hildrew, 1993; Suren and Lambert, 2010).

In this regard, previous studies concentrated on temperate zones, where the increased discharges from floods (i.e., hydrological pulses) and the reductions from droughts are clearly differentiated (Rolls et al., 2012; Leigh, 2013; Calapez et al., 2014). For instance, Suren and Jowett (2006) described clear variations in the composition and structure of aquatic communities between samples taken before and after flood or drought events. Following flood events of varying magnitude, significant decreases in the density and species richness of aquatic communities have been observed (Suren and Jowett, 2006; Robinson, 2012). On the other hand, it has been noticed that the effect of droughts on benthic communities depends on the duration of such events. When the duration is long, the area available for macroinvertebrate communities decreases, causing a dramatic decline in the density and species richness (Wood and Armitage, 2004; Mouthon and Daufresne, 2006).

In tropical zones, the climate is characterised by marked seasonality between wet and dry periods (Flecker and Feifarek, 1994); however, these seasons are less pronounced in the south Andean region of Ecuador due to the strong effect of the Andes range (Nouvelot et al., 1995; Buytaert et al., 2006). This range influences the specific characteristics of every fluvial network (discharge, vegetation cover, slope and substrate type), the air mass transferences and the transition zones between ecosystems, which affect the frequency, intensity, and amount of rainfall and, therefore, the volume and frequency of water reaching the rivers (Nouvelot et al., 1995; Bispo et al., 2006; Buytaert et al., 2006).

Studies at medium altitude in the Andean region report a decrease in the density and species richness on the seasonal and annual time scales mainly due to an increase in shear stress during heavy floods in the rainy season (Jacobsen and Encalada, 1998; Ríos-Touma et al., 2011; Mesa, 2012). In the high Andes, only few of such studies have been carried out. For example, Moya et al. (2009) studied in Bolivian streams, at elevations higher than 3,000 $\mathrm{m}$ above sea level (a.s.l.), the effect of variations in streamflow on the density and species richness, although with a very 
limited sampling period and seasonal variability. They concluded that seasonality is not a critical factor for the richness or density of macroinvertebrates in the riffles, except for the EPT taxa richness. With other words, aquatic communities at these altitudes seem not to be regulated only by seasonal features but also by aspects such as (i) the susceptibility of taxa to disturbances; (ii) the taxa ability to recolonise habitats; (iii) the number of colonising taxa; and (iv) the number of life cycles of the colonisers.

The influence of hydrology on the natural dynamics of macroinvertebrate communities is very relevant for the conservation of the delicate High-Andean ecosystems. In this context, Ecuadorian regulations require environmental flow assessments for hydroelectricity projects, which normally are located at high elevations and carried out within the frame of consulting works, little of this information is linked to the aquatic habitat density and composition, with the exception of a few efforts such as Herrera and Burneo (2017). In those studies, in general only a very limited set of hydrological indices are defined for estimating the monthly environmental flow but not for inspecting the effect of hydrological extreme events on the dynamics of the aquatic communities. Indeed, it is worth noticing that no one of the recently cited studies in tropical zones are considering hydrological indices to explore the effects of peaks and low flows on the aquatic community.

In temperate zones recent studies are focusing on defining discharge thresholds, both for flooding and drought events, that significantly affect aquatic communities in natural (Wood et al., 2000; Suren and Jowett, 2006; Monk et al., 2007; Chang et al., 2008) and altered rivers (Freeman et al., 2001; Armanini et al., 2014; Macnaughton et al., 2015). The studies on altered ecosystems focus particularly on the effects on fish (i.e., Freem et al., 2001; Armstrong, 2003; Macnaughton et al., 2017) and less on macroinvertebrates (Armanini et al., 2014; Miller et al., 2014) concentrate on the temporal variability of the aquatic communities as a function of the season in the year (Jacobsen and Encalada, 1998; Ríos $\square$ Touma et al., 2011; Mesa, 2012) discharge (i.e. hydrological) thresholds and their impact on aquatic communities. Exceptions hereon are the studies in altered rivers of Castro et al. (2013), Miserendino (2009), Herrera and Burneo (2017) that macroinvertebrates, and Lima et al. (2018) and García et al. (2011) of fish.

In contrast to previous studies, this study assessed for the first time in an Andean microcatchment with an elevation higher than 3,500 $\mathrm{m}$ a.s.l. the effect of extreme hydrological events (characterised by both, suitable hydrological indices and flow thresholds) on community changes. The mesohabitat spatial scale was selected for this study, in line with a previous study on the same site (Vimos-Lojano et al., 2017), which demonstrated that the distribution of aquatic communities is directly related to the physical characteristics of the habitat at this spatial scale. Further, as stated by Brunke et al. (2001) this scale provides a more appropriate approach to study the composition and structure of the community as a function of the fluctuation of flow in streams and rivers. Thus, the main objective of the research presented herein was to discern the effects of 
the Large Peak flow (LPF), Small Peak flow (SPF) and Low flow (LF) events on the aquatic macroinvertebrate community in the headwaters of an Andean microcatchment with an elevation higher than 3,500 $\mathrm{m}$ a.s.l. Specifically, it was aimed at answering the following research questions: (i) which hydrological indices related to LPF, SPF and LF events are fundamental to explain the changes in the community's structure and composition?; and (ii) what are the changes one can observe in the community as a result of the referred hydrological events?.

\section{MATERIALS AND METHODS}

\section{Study site}

Four streams were selected in the headwater of the Zhurucay river microcatchment $\left(7.5 \mathrm{~km}^{2}\right)$, belonging to the Jubones river catchment. The microcatchment is located in southern Ecuador (9662500 m N, $9658750 \mathrm{~m} \mathrm{~S}, 694630 \mathrm{~m} \mathrm{~W}$ and $698010 \mathrm{~m} \mathrm{E}$; UTM coordinate system, Zone 17S, geoid PSAD56) at approximately 3,600 $\mathrm{m}$ a.s.l. (Fig. 1). The dominant vegetation type is grassland (Tussock grass, 58.6\%, Calamagrostis intermedia,) with few patches of Quinoa trees (17.5\%; Polylepis incana Kunth and Polylepis reticulata Kunth) and sparse small shrubs. There is a low degree of human intervention, consisting mainly of non-intensive farming activities (Hampel et al., 2010; Studholme et al., 2017).

Climate in the region is characterised by the constant presence of fog and drizzle and annual (bimodal) rainfall average is approximately $1,289 \mathrm{~mm}$. Six years of historical precipitation data were available, and the lowest rainfall occurred in the period June to September (minimum and maximum average of $65.97 \mathrm{~mm}$ and $113.73 \mathrm{~mm}$ respectively) while the rainy season stretches from October to May. February was the month with the highest inter-annual fluctuation in precipitation, with a maximum monthly value of $257 \mathrm{~mm}$ and a minimum value of $40.2 \mathrm{~mm}$. The average daily temperature during the whole study period was $5.9^{\circ} \mathrm{C}$ and the relative humidity ranged between $82 \%$ and $91 \%$ (Padrón, 2013). The seasonal variation of temperature is very low (i.e. minimum daily average of $4.8^{\circ} \mathrm{C}$ in July of 2011 , the maximum daily average of $6.7^{\circ} \mathrm{C}$ in November of 2011), while daily temperature fluctuation can exceed $15^{\circ} \mathrm{C}$.

With respect to the hydraulic conditions, the maximum velocity recorded throughout the sampling period (December 2011 to October 2013) was $1.51 \mathrm{~m} \mathrm{~s}^{-1}$, with an average of $0.31 \pm$ $0.012 \mathrm{~m} \mathrm{~s}^{-1}$. The highest Froude number $\left(F_{r}\right)$ was 1.35 , with an average of $0.27 \pm 0.011$. The maximum water depth was $0.49 \mathrm{~m}$, with an average of $0.16 \pm 0.004 \mathrm{~m}$. The maximum stream channel width and slope were $1.61 \mathrm{~m}$ y 0.05 respectively. These hydraulic variables were recorded when the average discharge fluctuated between $33.91 \mathrm{~s}^{-1}$ and $352.11 \mathrm{~s}^{-1}$. The four studied streams, are characterised by a large substrate heterogeneity dominated by angular rocks, consisting of dominant cobbles $>50 \%$ (between 60 and $250 \mathrm{~mm}$ ) and pebbles about 25\% (between 20 and 60 $\mathrm{mm}$ ) in a matrix of gravel about 20\% (between 0.2 and $20 \mathrm{~mm}$ ) and sand about 5\% (0.006 and $0.2 \mathrm{~mm}$ ). Additional hydrological and hydraulic characteristics of the studied stream reaches are 
presented in Annex A.

\section{Sampling methods}

50-m-long reaches in each of the four selected streams were sampled in the period between December 2011 and October 2013. Five cross-sections were established in each of the four 50m-long reaches. A total of 19 sampling campaigns were carried out. A wide variety of hydrological conditions (wet and dry) was recorded in this period.

\section{Sampling of abiotic data}

In each sampling campaign, hydraulic measurements were taken at the biological sampling points located at the center of each of the five cross-sections. Were measured the water depth (m), width of the water surface (m) and average velocity $\left(\mathrm{m} \mathrm{s}^{-1}\right)$ at $60 \%$ of the water depth from the water surface (Wyżga et al., 2012) using a propeller flow meter (HydroMate CMC3, Sydney, Australia). Additionally, information regarding water levels was recorded at gauging stations located in each of the streams under study using the Mini-Diver DI1501 and Baro-Diver DI500 pressure sensors (Schlumberger Water Services, France) considering a measurement interval of 5 min. These water level data were converted to discharge data according to appropriate hydraulic equations for gauging weirs with known geometry and free spill (Chow et al., 1988); a process that was validated using the data recorded by the propeller flow meter. These sub-daily discharges were averaged to daily values by means of a simple arithmetic averaging process. The substrate was visually classified using six groups that were defined based on the simplified classification of Elosegi (2009), considering $25 \times 25 \mathrm{~cm}^{2}$ reference quadrants.

\section{Sampling of biotic data}

Macroinvertebrate samples were collected each campaign using a modified Surber net (coverage area: $625 \mathrm{~cm}^{2} ; 250-\mu \mathrm{m}$ net mesh opening; sampling effort: $30 \mathrm{~s}$ ) vigorously stirred by hand, located near the center of each cross-section and the substrate. The collected sample was placed in a plastic bottle, preserved in a solution of $4 \%$ formalin and transferred to the laboratory, where the organisms were separated and identified to the genus level with the use of a stereomicroscope (Olympus SZ-6145TR, Japan) and species identification keys. Nevertheless, some non-insect specimens were identified at a higher taxonomic level (i.e., Hydrachnidia, Gasteropoda, Oligochaeta, and Sphaeriidae), including organisms of the Chironomidae family and the larvae of the Xiphocentronidae family whose taxonomical identification is complex (Domínguez et al., 2009; Acosta and Prat, 2010).

\section{Hydrological and biological data processing}


The daily discharge values were transformed into daily values of volume per unit catchment area $(\mathrm{mm})$ to derive a single comparative scale of the discharges of the four studied streams (Chow $e t$ al., 1988). Then, the arithmetic mean $\left(\mathrm{Q}_{\mathrm{aver}}\right)$ of the transformed daily discharges were calculated $\left(\mathrm{Q}_{\mathrm{s} 1}, \mathrm{Q}_{\mathrm{s} 2}, \mathrm{Q}_{\mathrm{s3}}\right.$ and $\left.\mathrm{Q}_{\mathrm{s} 4}\right)$ to obtain a single series of representative discharges and derive one single set of hydrological indices. For assessing the similarity (i.e. representativeness) of $\mathrm{Q}_{\text {aver }}$ regarding the magnitude and evolution of flow, a comparative analysis was made between $\mathrm{Q}_{\mathrm{aver}}$ and the individual daily hydrographs of the studied streams by means of three complementary procedures. The procedures applied at each of the monitored streams consisted in: (i) evaluation of the correlations between the magnitudes of the discharges and $\mathrm{Q}_{\text {aver; }}$; (ii) calculation on a daily basis of the coefficient of variation $(\mathrm{CV})$ using the discharge of the four streams in the same day of interest and the average of the entire timeseries of daily $\mathrm{CV}\left(\mathrm{CV}_{\text {aver }}\right)$, which constitutes an index of similarity among the discharges of the four monitored streams; and (iii) comparison of the evolution and magnitude of the duration curves of the average daily discharges.

Accordingly, $\mathrm{Q}_{\text {aver }}$ was used in this study to calculate 27 hydrological indices (Table 1) for each sampling campaign, which were defined based on Monk et al. (2006) and Chang et al. (2008). No specific indices of the duration of peak flows were computed, because peak events had an average duration of 1 day equal to the time basis of the daily discharge values. In line herewith, no indices of low flow duration were determined but, instead, different LF durations were explicitly considered in the analysis (i.e., 10, 30, 60, 75, 90, 115, and 140 days). For the identification of hydrological peaks, relevant to the present study, thresholds were defined based on the analysis of the series of discharge events that occurred in the one-year period prior to every sampling date.

Thus, for $\mathrm{Q}_{\text {aver }}$ and considering exceedance percentiles, large peak flows (LPfs) were defined as (see Fig. 2) flows with a value higher than the percentile $2 \%\left(\mathrm{Q}_{2}=130 \mathrm{~mm}\right)$; values between the percentile 5\% $\left(\mathrm{Q}_{5}=70 \mathrm{~mm}\right)$ and $\mathrm{Q}_{2}$ were considered small peak flows (SPFs); and values lower than the percentile $75 \%\left(\mathrm{Q}_{75}=8 \mathrm{~mm}\right)$ were considered low flows (LFs). Two or more peak flow pulses (LPFs and/or SPFs) were grouped together if the time lag between successive pulses was shorter than 20 days; this group of peak pulses was considered as a single (global) peak flow event (for instance, LPF 5 and LPF 7 in Fig. 2). For the calculations of the hydrological indices, the date of the last of these grouped peak pulses was adopted as the date of the global peak event. This consideration is based on the fact that a period shorter than 20 days is not enough for observing a complete recovery of the aquatic communities (Flecker and Feifarek, 1994).

On the contrary, a LF event was defined if the discharge was lower than or equal to $\mathrm{Q}_{75}$ (Yulianti and Burn, 1998) during a period of at least 7 days. The extent of this event lasted until a water pulse more than $\mathrm{Q}_{10}(45 \mathrm{~mm})$ occurred. The $\mathrm{Q}_{10}$ threshold was defined in this study based on the comparison of the effects of different pulses on the community metrics recorded in 
successive sampling campaigns (i.e., comparing campaigns 5 with 6,6 with 7, 7 with 8,8 with 9 , 16 with 17, 17 with 18 and 18 with 19); in this context, water pulses with magnitudes lower than $\mathrm{Q}_{10}$ did not cause significant effects on the community metrics. Therefore, campaign 5 is not part of the LF event 5 (Fig. 2), despite being preceded by 7 days of discharges lower than $\mathrm{Q}_{75}$, since immediately after it a pulse higher than $\mathrm{Q}_{10}$ was recorded.

Two tests were carried out to inspect on the congruency of the magnitude of the above defined discharge thresholds, namely (i) an extreme value (hydrological) analysis (EVA); and (ii) a comparison of the $\mathrm{Q}_{2}$ threshold with the discharge threshold for substrate movement $\left(\mathrm{Q}_{\text {subst }}\right)$. In this context, the EVA was conducted to verify that the SPF and LPF events defined by $\mathrm{Q}_{5}$ and $\mathrm{Q}_{2}$ are part of the population of independent extreme flows at the studied streams, that is, are hydrologically independent. If that is the case, the peak discharge thresholds used in this study (i.e. $\mathrm{Q}_{5}$ and $\mathrm{Q}_{2}$ ) should be greater than, or at least equal to, the minimum peak threshold $\left(\mathrm{Q}_{\mathrm{Hydrol}}\right)$ necessary to obtain an optimal fitting of the time series of daily peaks to a generalised (extreme value) Pareto distribution (GPD; Pickands, 1975; Vázquez et al., 2009). Hence, the peak discharge data fitting was performed using the peak over threshold (POT) methodology. To this end, a series of daily extreme values was generated using the partial duration time series (PDS) methodology (Vázquez and Feyen, 2003; Vázquez et al., 2008). This PDS analysis was carried out with the aid of specific-task subroutines that were previously (Vázquez and Feyen, 2003; Vázquez et al., 2008) programmed with the FORTRAN and PERL (Practical Extraction and Report Language) programming languages.

Since, substrate movement is an important factor influencing the composition and structure of communities (Milhous and Bradley, 1986), a second test on $\mathrm{Q}_{2}$ was performed to check on whether it is likely to produce substrate movement. Thus, for each of the four studied streams, $\mathrm{Q}_{\text {subst }}$ was generated using the equation of Milhous (Milhous, 1998); further, these values were averaged into a single one that was finally compared to $\mathrm{Q}_{2}$. The Milhous equation considers the relationship between the hydraulic radius (depending on the circulating flow), the slope and the physical properties of the riverbed, and the shear stress required by the substrate to start moving. Given the physical properties of the riverbed substrates in the study sites, shear stress was considered to be a dimensionless constant with a value of 0.050 (Milhous and Bradley, 1986; Olsen et al., 2014).

With regard to the biological data, rare taxonomic groups (relative abundance less than $0.01 \%$ with regard to the total number of individuals; Kennen et al. (2010)) were removed. Several community metrics were calculated, such as individual density $\mathrm{m}^{-2}$ (density), total taxa richness, Pielou's evenness (evenness), and the Shannon-Wiener diversity index (diversity), using the PRIMER statistical software (Version 6; Ivybridge, UK). 
In addition, the EPT (Ephemeroptera, Plecoptera and Trichoptera) relative abundances, EPT taxa richness, and the non-insect taxa richness were calculated. Thus, the samples were grouped according to the type of mesohabitat, defined on the basis of the Froude number $\left(\mathrm{F}_{\mathrm{r}}\right)$, which is a function of the discharge and the hydraulic conditions of each sampling cross-section (Jowett, 1993). Hence, according to Jowett (1993) the different mesohabitats are pool $\left(F_{r}<0.18\right)$, run $\left(0.18 \leq F_{r} \leq 0.41\right)$ or riffle $\left(F_{r}>0.41\right)$. Furthermore, the 10 most abundant taxa, representative of each mesohabitat, were chosen, and their relative abundances were calculated (Suren and Jowett, 2006) for further analysis.

\section{Statistical analysis}

To answer the first question of the study, concerning which hydrological indices related to LPF, SPF and LF events are determinant to explain the changes in the community's structure and composition at high-Andean streams, a multiple regression analysis in successive steps (Monk et al., 2006; Suren and Jowett, 2006) was performed between the hydrological indices and the response variables (community metrics and relative abundances of taxa). For every predictor included in the regression analysis, the beta (standardised regression) coefficient $(\beta)$, measuring how strongly each predictor influences the dependent variable, was calculated. The $\beta$ have a tvalue and significance of the $\mathrm{t}$-value (the $\mathrm{p}$-value) associated with this. If the t-value is significant, then the $\beta$ is significantly different from zero and, as such, significantly predicts the dependable variable. Hereafter, in this study, the stronger predictors were always considered for the description of the results and the respective discussion; the absolute values of their associated $\beta$ were always at least 0.25 (i.e., subjectively, this absolute value was adopted herein as a minimum $\beta$ threshold). Prior to the multiple regression analysis, redundant hydrological indices from each mesohabitat type were discarded (considering the correlation analysis parameters Spearman rho $>0.7, p \leq 0.05$ ) using the SPSS software (version 20; IMB/SPSS, Inc., Armonk, New York). A total of 20,18, and 17 indices were included in the statistical analysis for the pool, run, and riffle mesohabitats, respectively.

Regarding the second research question, concerning what changes can be observed in the community as the result of peak (LPF and SPF) and LF events, the differences in community metrics and the relative abundance of the 10 most dominant taxa, before and after events, were analysed for each mesohabitat. In addition, in the case of LF events, changes occurring in the community metrics and relative abundances of taxa were analysed throughout the entire LF periods. Specifically, the biological variables were compared, in terms of time, between the first sampling campaign occurring in the LF period and the posterior campaigns that are included in the same LF period. These differences were statistically analysed by means of the PERMANOVA test based on the Bray-Curtis similarity analysis (Anderson, 2001; Suren and Jowett, 2006) using 
the PAST software (version 3.08; Øyvind Hammer, Natural History Museum, University of Oslo).

\section{RESULTS}

A total of 361 biological samples were analysed between December of 2011 and October of 2013. The number of aquatic macroinvertebrate specimens identified was 106,996, belonging to 38 different taxonomic groups (with an average density of 5,604 ind. $\mathrm{m}^{-2}$ ) as detailed in Annex B. The Orthocladiinae subfamily was the most dominant taxon, accounting for $31.3 \%$ of all individuals, followed by the Girardia genus with $24.0 \%$, the Chironominae subfamily with $7.2 \%$, and Hyalella with $7.1 \%$. The other taxa did not exceed individually the $5.0 \%$ of all individuals. The most frequent taxa (present in over $80 \%$ of the samples) were Orthocladiinae, Hyalella, Girardia, Hydrachnidia, and Austrolimnius.

The recorded discharges at the four study sites exhibit significant correlations among them. In what follows $\mathrm{Q}_{\mathrm{Si}}$ stands for the discharge observed in the i-th stream, with $\mathrm{i}=1,2,3$ and 4 (Fig. 1). Regarding the correlation between $Q_{\text {aver }}$ and each of the monitored time series, the range of values of the Pearson correlation coefficient varied between 0.95 for $\mathrm{Q}_{\mathrm{S} 4}$ to 0.97 for $\mathrm{Q}_{\mathrm{S} 1}$. Additionally, the current study suggested an acceptable similarity (i.e., low value of $\mathrm{CV}_{\text {aver }}=0.39$ ) of the magnitude and temporal variability of the daily discharge series. The analysis of the duration curves of the daily flows confirmed the latter. Given the similar hydrological behaviour were the collected samples grouped in the statistical analysis.

The EVA showed that the time series of daily peaks optimally fitted an exponential distribution (a particular case of a GPD) for peak values greater than or equal to $\mathrm{Q}_{\text {Hydrol }}=52.6$ $\mathrm{mm}$. This hydrological threshold is lower than both $\mathrm{Q}_{2}=130 \mathrm{~mm}$ and $\mathrm{Q}_{5}=70 \mathrm{~mm}$, implying that the LPF and SPF events defined in this study, based on $\mathrm{Q}_{2}$ and $\mathrm{Q}_{5}$, follow the extreme value exponential distribution and, as such, are part of the population of independent extreme flows in the studied streams; that is, are hydrologically independent. Further, the average $\left(\mathrm{Q}_{\text {subst }}\right)$ of the threshold values generated for each stream by the method that is based on the equation of substrate movement (Milhous, 1998) was $119.8 \pm 6.6 \mathrm{~mm}$. It is lower than $\mathrm{Q}_{2}$, suggesting that the events defined herein as LPF had a significant effect on the community metrics and taxa due to the implicit mobilisation of the benthic substrate.

\section{Key hydrological indices}

A total of 15 hydrological indices were identified by the multiple regression analyses as being influential on the following aspects: (i) community metrics; and (ii) the relative abundance of the 10 most abundant taxa. Of both aspects, eight variables were influential in the pool mesohabitats, four in the run mesohabitats and six in the riffle mesohabitats (Table 2). Some of the hydrological indices were important in more than one of the mesohabitats. 
In the pool mesohabitats, the multiple regression analyses on the LPF variables revealed that with absolute values higher than 0.33 of the $\beta$ (i.e., standardised slope of the regression) negative correlations were obtained between MAXDAYQ(7) and density, and FH(1) and total taxa richness and ETP taxa richness (Table 2 and Annex C). On the other hand, also with a $\beta$ absolute value of 0.33 , the LF index FL(3) was negatively correlated with EPT taxa richness. In taxonomic terms, two dominant non-insect taxa were recorded (Annex D), namely, the Helobdella genus (42.6\%) and the Lymnaeidae family (15.9\%). With $\beta$ absolute values higher than 0.25 , the LPF indices FH(4) and MAXDAYQ(60) were negatively correlated with Lymnaeidae dominant taxa. With similar $\beta$ absolute values the LF index QMIN(1) was positively correlated with Hydrachnidia and Heterelmis (Annex D).

In the run mesohabitats, the multiple regression analyses on the LPF variables indicated that, with $\beta$ absolute values above 0.40 , negative correlations were recorded between MAXDAYQ(7) and density, $\mathrm{FH}(2)$ and total taxa richness, and $\mathrm{FH}(3)$ and non-insect richness and diversity. With $\beta$ absolute values higher than 0.30 , some LF variables exhibited a positive correlation, namely, QMIN(1) and FL(1) with the density, and COMINDAY with evenness and diversity (Table 2 and Annex C). In taxonomic terms, Girardia was the main dominant taxa, representing $27.8 \%$ of the community, followed by the Chironominae with $6.1 \%$ (Annex D). With $\beta$ absolute values over 0.4 , the LPF variable $\mathrm{FH}(3)$ was negatively correlated with the relative density of Chironominae (Annex D).

The multiple regression analyses on the LPF variables in the riffle mesohabitats showed that with $\beta$ absolute values higher than 0.30 , negative correlations were obtained between $\mathrm{FH}(2)$ and the total taxa richness, $\mathrm{FH}(4)$ and non-insect richness, and COMAXDAY and diversity. Furthermore, the LF variable QMIN(1) showed a negative correlation with density (Table 2 and Annex C). In taxonomic terms, Hyalella is the most dominant taxon representing $10.1 \%$ of the community, followed by Metrichia (Tricoptera), with 9.8\% (Annex D). With $\beta$ absolute values exceeding 0.25 , the LPF variable FL(1) was negatively correlated with the relative abundance of Metrichia (Annex D).

With regard to the analysis of antecedent peak flow conditions, some hydrological indices such as MAXDAYQ(7), COMAXDAY, FH(1) and FH(2), indicated the time-accumulated effects of past high flow events (i.e. antecedent conditions) on the community structure at a given sampling date (Table 2). In this context, the density, the EPT and the non-insect relative abundances and the different metrics of richness (total, non-insect and EPT) and the diversity exhibited changes owing to peaks occurring between 7 and 120 days prior to sampling dates. Specifically, in the pool mesohabitats the most important hydrological indices (MAXDAYQ(7) and $\mathrm{FH}(1)$ ) showed an effect of past peak flows on the community between 7 and 30 days. In the run mesohabitats the effects of past peaks occurring longer ago from the sampling dates (up to 90 
days) were noticed through the indices MAXDAYQ(7), $\mathrm{FH}(1) \mathrm{FH}(2)$ and $\mathrm{FH}(3)$. In the riffle mesohabitats the effects of past peaks happening even longer ago (up to 120 days) from the sampling dates were reflected by the indices COMAXDAY, FH(2) and FH(4).

\section{Effect of peak and low flow events}

Figure 3 shows the temporal variation of the community metrics as a function of the flow in the pool, run, and riffle mesohabitats throughout the study period. The general trend in density (Fig. 3a) was positive in the LF periods increasing up to approximately 30,000 ind. $\mathrm{m}^{-2}$ in the run mesohabitats; for the other mesohabitat types (pool and riffle) the density values were always less than 13,000 ind. $\mathrm{m}^{-2}$. In terms of the total taxa richness (Fig. 3b), the results showed higher values in the three types of mesohabitats during LF events. However, this trend was not observed for the EPT taxa richness (Fig. 3c), as this metric fluctuated significantly throughout the period of analysis. Furthermore, it was observed that the EPT relative abundance (Fig. 3d) increased with flooding and decreased with LFs in the run and riffle mesohabitats; these differentiated trends were not that obvious in the pool mesohabitats.

To evaluate the effects of the different hydrological events on the community metrics and relative abundance of the 10 most abundant taxa, the sampling campaigns are numbered in Fig. 2 following a chronological order. With respect to the assessment of the effects of LPFs on the communities, the LF campaigns that are immediately posterior to these peak events are compared to the respective ones that are preceding them. Hereafter, the LF campaigns that are posterior to LPFs (i.e., for LPF 5, campaigns 3 and 4; for LPF 6, campaign 12; and for LPF 7, campaign 15) were compared to the preceding LF campaigns (i.e., for LPF 5, campaigns 1 and 2; for LPF 6, campaign 11; and for LPF 7, campaign 13, although this latter campaign, similarly to campaign 12 , is not strictly a LF campaign, given that the duration of the respective LF event was shorter than 7 days). On the other hand, campaigns 10 and 11 preceding and proceeding a SPF (Fig. 2) were compared for evaluating whether the SPF in between had any effect on the communities. In the same context, campaigns 13 and 14 were as well compared. Although no other SPF were recorded in the studied period, some events, smaller in terms of magnitude than SPFs were also studied. Concretely, three events were analysed, respectively, by the following preceding and proceeding campaigns: 1 and 2, 5 and 6, and 9 and 10 (Fig. 2). The applied PERMANOVA analysis suggested no significant differences in community metrics among the respective campaigns (i.e., 1 and 2, 5 and 6, and 9 and 10) and, as such no significant effects of the inspected small events.

The LPF value of $160.4 \mathrm{~mm}$ (LPF 5) on community metrics led to a significant decrease in the density in the three studied mesohabitats (Table 3). However, the LPF of $131.7 \mathrm{~mm}$ (LPF 6) only had a negative effect on the density in the riffle mesohabitats. Positive effects of LPFs on 
evenness were observed in the pool mesohabitats after LPF 5 and in the riffle mesohabitats after LPF 6. In addition, LPF 5 exerted a negative influence on the total taxa richness in the pool and run mesohabitats. A positive effect occurred in terms of the EPT relative abundance in the pool (after LPF 7), run (after LPF 5 and LPF 6) and riffle (after LPF 5) mesohabitats. In the pool and riffle mesohabitats produced LPF 7 an increase in the relative abundance of Hydrachnidia, while in the run mesohabitats LPF 5 produced an increase in the relative abundance of Metrichia $(7.5 \%)$ and a decrease in the relative abundance of Girardia genus (-16.1\%) and Chironominae subfamily $(-9.2 \%)$. The relative abundance of Oligochaeta exhibited two different responses, i.e., firstly, an increase (7.9\%) with a discharge of $131.7 \mathrm{~mm}^{-1 a y^{-1}}$ and a decrease $(-2.9 \%)$ with a higher discharge of $160.4 \mathrm{~mm} \mathrm{day}^{-1}$. In the riffle mesohabitats, after LPF 5, a sharp decline was observed in the proportion of the relative abundance of Girardia (-21.1\%). Further, positive effects of LPF 7 on Contulma (6.4\%) were observed.

The events of maximum duration of LF (Fig. 2) started in campaigns 6 (LF 5) and 16 (LF 9). To observe changes in the community during LF events, the samples from campaigns 6 and 16 were compared respectively with the samples from the posterior campaigns (i.e., for LF 5, campaigns 7, 8 and 9; and for LF 9, campaigns 17, 18 and 19). In the pool mesohabitats, a major density increase was observed in the first 90 days with LFs (Table 4); the opposite effect was observed for evenness and diversity. When the period was longer, i.e. 115 days, a further increase in the density was noticed. The total taxa richness was reduced (-3.5 taxa) in the first 10 days with LFs; however, the opposite trend was observed (11.8 taxa) after 30 days with LFs. After 30 days with LFs the relative abundance of EPT was reduced with 12.7\%. With LFs, the EPT taxa richness exhibited a negative tendency after 10 days, which was maintained after 115 days. Regarding the taxa, the relative abundance of Psychoda genus decreased (-4.7\%) over the first 30 days with LFs; however, this trend reversed after a longer LF event (115 days). In addition, a 5.2\% decrease was observed in the relative abundance of Hydrachnidia over a period of 30 days. In the run mesohabitats, a negative effect was observed on the density after 75 and 115 days, and in the total taxa richness after 115 days. Furthermore, a significant increase in the relative abundance of the Orthocladiinae subfamily (8.6\%) was observed over a LF period of 115 days. No significant trends were noticed in the riffle mesohabitats.

\section{DISCUSSION}

\section{Use of hydrological indices}

The use of hydrological indices to assess the effects of extreme flow conditions on the dynamics of aquatic communities increased in the last decade (Wood et al., 2000; Belmar et al., 2012; Greenwood and Booker, 2015). According to Greenwood and Booker (2015) affect flow conditions directly the diversity, abundance and composition of aquatic communities. In this context, this study aimed at examining the effect of river flow on aquatic communities in the high 
Andean region above 3,500 $\mathrm{m}$ a.s.l., more in particular the influence of antecedent peak events. The multiple regression analysis showed that the impact of high discharge events (LPFs) on the density of macroinvertebrates in the pool and run mesohabitats is significant negative because of an increase in drag (Fig. 4). The rise in shear forces influence certain benthic taxa (Ríos-Touma et al., 2011; Rocha et al., 2012), mainly of the non-insect class (e.g. Lymneidae, Girardia) (RiosTouma et al., 2012), which do not have body features to cope with the increase in shear stress associated with high flow conditions (Tomanová and Usseglio-Polatera, 2007). For instance, Lymneidae lacks legs, supporting structures, to cope with flooding (Lam and Calow, 1988; RiosTouma et al., 2012).

In the run and riffle mesohabitats leads an increase in drag during flooding to a decrease in the diversity and total taxa richness. Sueyoshi et al. (2014) suggested that some of the taxa leaving other mesohabitats end up in pools, characterised by lower hydraulic stresses, given that connectivity between mesohabitats is warranted (Pringle, 2001). In this study area, situated at an altitude above 3,500 $\mathrm{m}$ a.s.l. and significant slopes, the multiple regression analysis does not indicate an increment in diversity in the pool mesohabitats; further, the total and the EPT richness, indirect measures of diversity, exhibit a decrement. This, notwithstanding, as depicted in Fig. 4, pool mesohabitats are the ones with the gentlest conditions, even during peak events. However, it has to be noticed that the pools in our study are smaller, steeper and less isolated than the ones studied for instance by Sueyoshi et al. (2014); as such, they can be affected more by high flow events.

The above discussion does not account for the time variability and is based solely on the analysis of the density and diversity metrics. When the rest of the metrics and the time variability are included in the analysis, then the current study suggests that, with regard to a sampling date, antecedent peak events have a very decisive influence on the aquatic community composition at that particular date. Further, the study points out which type of mesohabitats is least affected (pool) in time by the antecedent peak flow conditions and which one the most affected (riffle) (Table 2). As shown in Fig. 4 are the pool mesohabitats the gentlest environment for the aquatic communities under peak events; nevertheless they are not really a refuge for the dragged taxa. With respect to the change of taxa in the pool mesohabitats associated to peak events before the sampling date, an important increase of relative abundance of Helobdella and Hyalella (Annex D) was observed, notwithstanding their individual contribution as predictors in the multiple regression is relatively low. Both, Helobdella (Stubbington and Wood, 2013) and Hyalella (McElravy and Resh, 1991) have the capacity of hiding in the substrate, which makes them less sensitive to higher drag forces.

In the run mesohabitats was the genus Girardia, the second dominant group, negatively affected by peak events occurring 30 days before the sampling date. Tomanová and UsseglioPolatera (2007) reports that the orden Planaria, to which the genus Giardia belongs, possesses 
low ability to adhere to the bottom materials of the streams despite their flattened shape, explaining why the genus Girardia does not resist to significant discharges. At the other hand, Metrichia, owing to its body conditions (characteristics of the case), has the potential of adhering to the surrounding substrate (Barbero et al., 2013), which enables this genus to resist the drag forces associated to peak events. In both, the run and riffle mesohabitats, the Chironominae shows a decrease of relative abundance with peak events occurring between 90 (run) and 120 (riffle) days before the sampling date (Annex D). Similar to Girardia, this taxon lacks the capacity to adapt to significant discharges. An important invertebrate in the riffle mesohabitats is the genus Metrichia, which is negatively correlated to the low discharge indices. Most likely the decrease in drag, associated with low flow, makes that other organisms different from this taxon (i.e., Hyalella and Chironominae) gradually enter and re-colonise these mesohabitats (Townsend and Hildrew, 1976), decreasing the relative abundance of Metrichia.

\section{Effect of hydrological events on aquatic communities}

In aquatic ecology the drag forces associated to LPFs are known as being catastrophic (Melo and Froehlich, 2004; Snyder and Johnson, 2006), producing serious repercussions on benthic biodiversity (Belmar et al., 2012; Mesa, 2012) and even altering the hydromorphological conditions of a river (Belmar et al., 2012; Mesa, 2012; Worrall et al., 2014). In this study, the $\mathrm{Q}_{2}$ $(130 \mathrm{~mm})$ discharge threshold that defines the LPF events is higher than the $\mathrm{Q}_{\text {subst }}=119.8 \mathrm{~mm}$ (mean velocity $=0.99 \mathrm{~m} \mathrm{~s}^{-1}$ ) for substrate movement, and likely affects certain aquatic communities owing to substrate movement as observed in other studies carried out at different latitudes (Cobb et al., 1992).

Lake (2000) describes two types of peak perturbations, i.e., (i) extreme events of high magnitude and of very short duration, known as pulses, that drastically reduces the density and species richness in the community; and (ii) continuous variation of the discharge and the presence of high peaks over time, known as ramps, that reduce the re-colonisation capacity of all taxa. In this study LPFs can be either type, namely LPF 6 in Fig. 2 can be considered as a pulse, whilst LPF 5 and LPF 7 may be regarded as being ramp events. Density decreased more than $60 \%$ and EPT relative abundance increased more than $15 \%$ in the three types of mesohabitats affected by either pulse or ramp type of peak event. Similar effects, although with different proportions of density decreased and EPT relative abundance increased from what is here reported, have been observed in several studies (Suren and Jowett, 2006; Worrall et al., 2014). Moreover, LPF effects were evident through the decrease in total taxa richness and density in the mesohabitats pool and run, which resulted in the increase of evenness in the pool mesohabitats.

The comparison of the metrics calculated before and after peak events confirmed what was concluded analysing the relationship between hydrological indices and community metrics, in the sense that less adapted aquatic taxa are more easily affected by peak events and their associated 
drag forces (Poff et al., 1997; Lamouroux et al., 2004; Bonada et al., 2007; Blanckaert et al., 2012). For instance, in the mesohabitats run and riffle a decrease in the proportions of Girardia and Chironominae after peak flows was observed, which indicates that the forms and structures of both pose little resistance to significant discharges, mainly due to their low ability to adhere to the bottom and bank material of streams (Tomanová, 2007). Hence, the negative effect on the abundances of Girardia and Chironominae possibly caused a significant increase in the proportion of individuals of the genus Metrichia in the run mesohabitats, favoured by their relatively small size and their preference to be attached to sites with thick substrates (Brooks et al., 2005; Barbero et al., 2013). Thus, in the run mesohabitat, it is likely that the organisms less adapted to the increase of discharge produced a faster re-colonisation of Metrichia, in comparison to organisms that arrived by the drift and which re-colonised with a slower rate (Townsend and Hildrew, 1976). In this regard, in stable environments, the genus Metrichia is less abundant and competitively inferior to other organisms with biological characteristics adapted more to low discharge conditions (Gibbins et al., 2001).

Further, LPF 6 had positive effects on Oligochaeta ratios, whilst LPF 5 had negative ones, confirming that these are two different types of peak events. LPF 5 previously had several continuous disturbances of high discharges which led to a loss of the interstitial zone of the reach (Bruno et al., 2010), and in turn to the sustained decline of the relative abundance of Oligochaeta. In contrast, LPF 6 was isolated in time, as well as the associated entrainment, allowing those organisms to settle down in the interstitial zone (Bruno et al., 2010), to remain and increase their ratios in relation to other groups. On the other hand, the effects of discharges of the evaluated LF events were lower than in other latitudes (Leigh, 2013) where magnitude and duration may cause large changes in aquatic communities (Rolls et al., 2012), since head or small streams are reduced to small intermittent pools, the only refuge for the aquatic biota at summer time (Dekar and Magoulick, 2007). This fact contrasts with the high Andean head streams, which maintain a permanent flow in the periods of low discharge due to the capacity of flow regulation of the surrounding soils, through absorption and retention (Crespo et al., 2012).

The observed response in the pool mesohabitats after a long period with low discharges was an increase in both, the density and the total taxa richness. For density, a similar increase was reported by Bogan and Lytle (2011) at pool mesohabitats in a temperate river, while, on the contrary, for the total taxa richness a decrease was observed by García-Roger et al. (2011) at pool mesohabitats also in a temperate river. In addition, a decrease of the proportions of EPT relative abundance and taxa richness was observed in pools which may be due to the sensitivity of the EPT to the decrease in discharge, as observed by Dewson et al. (2007), although, in riffle mesohabitats of several New Zealand rivers. Another factor that might influence the decrease in the proportion of EPT is the increase and dominance of certain taxonomic groups, generally belonging to the order Diptera (Psychoda), owing to their tolerance to low discharge conditions 
and to their short life cycles (Ledger et al., 2011); a tendency not observed in the current study (Table 4). On the contrary, in the run mesohabitats, LF conditions decreased the density and total taxa richness. There was a significant loss of individuals with prolonged LF periods (greater than 75 days), almost to what was reported by McIntosh et al. (2002) who, for riffle mesohabitats in the Iao river (Hawai), observed a decline of the community (density and total taxa richness) for LF periods longer than 100 days. In the present study, reduction of water depth and discharge may have influenced the area of the available habitats in LF periods (Rolls et al., 2012). Further, no response was observed on community metrics or taxonomic groups for low discharges in the riffle mesohabitats, suggesting that this type of events, characterised by low velocities, is of little importance to the aquatic communities in this type of mesohabitats. As already stated, the latter differs from the results found by McIntosh et al. (2002).

\section{CONCLUSIONS}

The presented research is unique in assessing the influence of hydrological events of different magnitude on aquatic communities in three different mesohabitats (i.e., pool, run and riffle) located above 3,500 $\mathrm{m}$ a.s.l. The observed peak events can be classified as pulses and ramps and were defined on the basis of the $\mathrm{Q}_{2}$ percentile, which is a much stronger discharge threshold than the ones commonly used to define peak events elsewhere. The latter suggests that the aquatic communities in high Andean streams have more resilience to peak flow variations and conditions than similar communities that live in streams at different latitudes and elevations. Further, either pulses or ramps dragged away organisms, particularly, from the run and riffle mesohabitats. The majority of these organisms did not refuge in pool habitats, as it has been reported in temperate and flat zones, except for few taxa. It is likely to be the result of the fact that the pools in our study are smaller (i.e., horizontally and vertically), steeper and less isolated than the ones studied elsewhere; as such, they can be affected more by peak events.

Different analyses coincided in the general idea that the dominant taxa with the least adapted body characteristics are the most sensible to peak events. In this context, some taxa belonging to the EPT groups, that pose suitable traits, were the ones less affected by peak conditions. When all metrics and time variability of peak events occurring prior to the sampling date were considered, then the current study suggests that, with regard to a sampling date, antecedent peak events are an important factor in evaluating the aquatic community composition at that particular date. Further, the study points out which type of mesohabitats is least affected (pool) in time by antecedent peak flow conditions and which one is most affected (riffle). The latter implies that in the current study site the pool mesohabitats were the gentlest environment for the aquatic communities under peak events, although they did not act as a permanent refuge for the dragged taxa. 
The study showed that peak flow events had stronger effects on the communities than low flows. Low flow events had less effects on the communities than the ones observed in temperate regions where streams tend to be intermittent under long low flow periods, which is not the case in high Andean streams because surrounding soil continuously provide water to the streams preventing stream intermittence. Further, in low flow events pools are important since different taxa can find suitable habitat whilst run mesohabitats are strongly impacted by the reduction of their area.

The current study may be considered as a first step towards future environmental flow assessments, a relevant task still to be done in South Andean regions under scientific considerations.

\section{ACKNOWLEDGEMENTS}

The authors would like to express their gratitude to the research and technical staff of the Aquatic Ecology Laboratory (LEA) of the Universidad de Cuenca (UC, Ecuador) for assisting on the field data collection and posterior laboratory analyses; and to the staff of project SENESCYT PIC 11715 for providing some hydrological data. This study was performed in the scope of the research project SENESCYT PIC-11-726, directed and co-directed respectively by the third and fourth authors, and financed by the Ecuadorian Secretary of Higher Education, Science, Technology and Innovation (SENESCYT), the National Electricity Corporation of Ecuador (CELEC EPHidropaute) and the Research Directory of the UC (DIUC). Further, financial support was provided by SENESCYT through a fellowship granted to the first author for carrying out his doctoral programme and through the PROMETEO fellowship awarded to the third author. The preparation of this manuscript is in line with the sabbatical leave programme of the fourth author. The authors are grateful to Nuria Bonada and Jan Feyen for their helpful comments on the first draft of this manuscript.

\section{REFERENCES}

Acosta, R., \& Prat, N. 2010. Chironomid assemblages in high altitude streams of the Andean region of Peru. Fundamental and Applied Limnology/Archiv für Hydrobiologie, 177, 5779.

Anderson, M.J. 2001. A new method for non $\square$ parametric multivariate analysis of variance. Austral Ecology, 26, 32-46.

Armanini, D., Chaumel, A.I., Monk, W., Marty, J., Smokorowski, K., Power, M., \& Baird, D. 2014. Benthic macroinvertebrate flow sensitivity as a tool to assess effects of hydropower related ramping activities in streams in Ontario (Canada). Ecological Indicators, 46, 466476.

Armstrong, J., Kemp, P., Kennedy, G., Ladle, M., \& Milner, N. 2003. Habitat requirements of Atlantic salmon and brown trout in rivers and streams. Fisheries research, 62, 143-170.

Barbero, M.D., Oberto, A.M., \& Gualdoni, C.M. 2013. Spatial and temporal patterns of macroinvertebrates in drift and on substrate of a mountain stream (Cordoba, Central Argentina). Acta Limnologica Brasiliensia, 25, 375-386. 
Belmar, O., Velasco, J., Gutiérrez $\square$ Cánovas, C., Mellado $\square$ Díaz, A., Millán, A., \& Wood, P. 2012. The influence of natural flow regimes on macroinvertebrate assemblages in a semiarid Mediterranean basin. Ecohydrology, 6, 363-379.

Bispo, P., Oliveira, L., Bini, L., \& Sousa, K. 2006. Ephemeroptera, Plecoptera and Trichoptera assemblages from riffles in mountain streams of Central Brazil: environmental factors influencing the distribution and abundance of immatures. Brazilian Journal of Biology, 66, 611-622.

Blanckaert, K., Garcia, X.F., Ricardo, A.M., Chen, Q., \& Pusch, M. 2012. The role of turbulence in the hydraulic environment of benthic invertebrates. Ecohydrology, 6, 700-712.

Bogan, M.T., \& Lytle, D.A. 2011. Severe drought drives novel community trajectories in desert stream pools. Freshwater Biology, 56, 2070-2081.

Bonada, N., Rieradevall, M., \& Prat, N. 2007. Macroinvertebrate community structure and biological traits related to flow permanence in a Mediterranean river network. Hydrobiologia, 589, 91-106.

Brooks, A.J., Haeusler, T., Reinfelds, I., \& Williams, S. 2005. Hydraulic microhabitats and the distribution of macroinvertebrate assemblages in riffles. Freshwater Biology, 50, 331344.

Brunke, M., Hoffmann, A., \& Pusch, M. 2001. Use of mesohabitat $\square$ specific relationships between flow velocity and river discharge to assess invertebrate minimum flow requirements. Regulated Rivers: Research \& Management, 17, 667-676.

Bruno, M.C., Maiolini, B., Carolli, M., \& Silveri, L. 2010. Short time-scale impacts of hydropeaking on benthic invertebrates in an Alpine stream (Trentino, Italy). Limnologica-Ecology and Management of Inland Waters, 40, 281-290.

Buytaert, W., Celleri, R., Willems, P., Bièvre, B.D., \& Wyseure, G. 2006. Spatial and temporal rainfall variability in mountainous areas: A case study from the south Ecuadorian Andes. Journal of hydrology, 329, 413-421.

Calapez, A.R., Elias, C.L., Almeida, S.F., \& Feio, M.J. 2014. Extreme drought effects and recovery patterns in the benthic communities of temperate streams. Limnetica, 33, 281296.

Castro, D., Hughes, R., \& Callisto, M. 2013. Influence of peak flow changes on the macroinvertebrate drift downstream of a Brazilian hydroelectric dam. Brazilian Journal of Biology, 73, 775-782.

Cobb, D., Galloway, T., \& Flannagan, J. 1992. Effects of discharge and substrate stability on density and species composition of stream insects. Canadian Journal of Fisheries and Aquatic Sciences, 49, 1788-1795.

Crespo, P., Feyen, J., Buytaert, W., Célleri, R., Frede, H.-G., Ramírez, M., \& Breuer, L. 2012. Development of a conceptual model of the hydrologic response of tropical Andean microcatchments in Southern Ecuador. Hydrology and Earth System Sciences Discussions, 9, 2475-2510.

Chang, F.-J., Tsai, M.-J., Tsai, W.-P., \& Herricks, E.E. 2008. Assessing the ecological hydrology of natural flow conditions in Taiwan. Journal of hydrology, 354, 75-89.

Chow, V.T., Maidment, D.R., \& Mays, L.W. 1988. Applied hydrology: McGraw-Hill. 572 pp

Dekar, M., \& Magoulick, D. 2007. Factors affecting fish assemblage structure during seasonal stream drying. Ecology of Freshwater Fish, 16, 335-342.

Dewson, Z.S., James, A.B., \& Death, R.G. 2007. Invertebrate community responses to experimentally reduced discharge in small streams of different water quality. Journal of the North American Benthological Society, 26, 754-766.

Domínguez, E., Fernández, H.R., \& Lillo, F.M. 2009. Macroinvertebrados bentónicos sudamericanos: Sistemática y biología: Fundación Miguel Lillo Tucumán. 656 pp

Elosegi, A. 2009. La estructura física de los cauces fluviales. In A. Elosegui and S. Sabater (Eds.), Conceptos y técnicas en ecología fluvial (pp. 71-84). Bilbao, España: Fundacion BBVA.

Flecker, A.S., \& Feifarek, B. 1994. Disturbance and the temporal variability of invertebrate assemblages in two Andean streams. Freshwater Biology, 31, 131-142. 
Freeman, M.C., Bowen, Z.H., Bovee, K.D., \& Irwin, E.R. 2001. Flow and habitat effects on juvenile fish abundance in natural and altered flow regimes. Ecological Applications, 11, 179-190.

García-Roger, E.M., del Mar Sánchez-Montoya, M., Gómez, R., Suárez, M.L., Vidal-Abarca, M.R., Latron, J., Rieradevall, M., \& Prat, N. 2011. Do seasonal changes in habitat features influence aquatic macroinvertebrate assemblages in perennial versus temporary Mediterranean streams? Aquatic Sciences, 73, 567-579.

García, A., Jorde, K., Habit, E., Caamaño, D., \& Parra, O. 2011. Downstream environmental effects of dam operations: changes in habitat quality for native fish species. River Research and Applications, 27, 312-327.

Gibbins, C., Dilks, C., Malcolm, R., Soulsby, C., \& Juggins, S. 2001. Invertebrate communities and hydrological variation in Cairngorm mountain streams. Hydrobiologia, 462, 205-219.

Greenwood, M., \& Booker, D. 2015. The influence of antecedent floods on aquatic invertebrate diversity, abundance and community composition. Ecohydrology, 8, 188-203.

Hampel, H., Cocha, J., \& Vimos, D. 2010. Incorporation of aquatic ecology to the hydrological investigation of ecosystems in the high Andes. MASKANA, 1, 91-100.

Herrera, I.A., \& Burneo, P.C. 2017. Environmental flow assessment in Andean rivers of Ecuador, case study: Chanlud and El Labrado dams in the Machángara River. Ecohydrology \& Hydrobiology, 17, 103-112.

Jacobsen, D., \& Encalada, A. 1998. The macroinvertebrate fauna of Ecuadorian highland streams in the wet and dry season. Archiv für Hydrobiologie, 142, 53-70.

Jowett, I. 1993. A method for objectively identifying pool, run, and riffle habitats from physical measurements. New Zealand Journal of Marine and Freshwater Research, 27, 241-248.

Kennen, J.G., Riva $\square$ Murray, K., \& Beaulieu, K.M. 2010. Determining hydrologic factors that influence stream macroinvertebrate assemblages in the northeastern US. Ecohydrology, 3, 88-106.

Lake, P. 2000. Disturbance, patchiness, and diversity in streams. Journal of the North American Benthological Society, 19, 573-592.

Lake, P. 2003. Ecological effects of perturbation by drought in flowing waters. Freshwater Biology, 48, 1161-1172.

Lam, P., \& Calow, P. 1988. Differences in the shell shape of Lymnaea peregra (Müller)(Gastropoda: Pulmonata) from lotic and lentic habitats; environmental or genetic variance? Journal of Molluscan Studies, 54, 197-207.

Lamouroux, N., Dolédec, S., \& Gayraud, S. 2004. Biological traits of stream macroinvertebrate communities: effects of microhabitat, reach, and basin filters. Journal of the North American Benthological Society, 23, 449-466.

Lancaster, J., \& Hildrew, A.G. 1993. Flow refugia and the microdistribution of lotic macroinvertebrates. Journal of the North American Benthological Society, 12, 385-393.

Ledger, M.E., Edwards, F.K., Brown, L.E., Milner, A.M., \& Woodward, G. 2011. Impact of simulated drought on ecosystem biomass production: an experimental test in stream mesocosms. Global Change Biology, 17, 2288-2297.

Leigh, C. 2013. Dry-season changes in macroinvertebrate assemblages of highly seasonal rivers: responses to low flow, no flow and antecedent hydrology. Hydrobiologia, 703, 95-112.

Lima, A.C., Sayanda, D., Agostinho, C.S., Machado, A.L., Soares, A.M., \& Monaghan, K.A. 2018. Using a trait $\square$ based approach to measure the impact of dam closure in fish communities of a Neotropical River. Ecology of Freshwater Fish, 27, 408-420.

Macnaughton, C.J., McLaughlin, F., Bourque, G., Senay, C., Lanthier, G., Harvey $\square$ Lavoie, S., Legendre, P., Lapointe, M., \& Boisclair, D. 2015. The Effects of Regional Hydrologic Alteration on Fish Community Structure in Regulated Rivers. River Research and Applications, 2, 249-257.

McElravy, E.P., \& Resh, V.H. 1991. Distribution and seasonal occurrence of the hyporheic fauna in a northern California stream. Hydrobiologia, 220, 233-246.

McIntosh, M.D., Benbow, M.E., \& Burky, A.J. 2002. Effects of stream diversion on riffle macroinvertebrate communities in a Maui, Hawaii, stream. River Research and Applications, 18, 569-581. 
Melo, A., \& Froehlich, C. 2004. Substrate stability in streams: effects of stream size, particle size, and rainfall on frequency of movement and burial of particles. Acta Limnologica Brasiliensia, 16, 381-390.

Mesa, L.M. 2012. Interannual and seasonal variability of macroinvertebrates in monsoonal climate streams. Brazilian Archives of biology and technology, 55, 403-410.

Milhous, R., \& Bradley, J. (1986). Physical habitat simulation and the moveable bed. Paper presented at the Water Forum'86: World Water Issues in Evolution, 1976-1983, New York, USA.

Milhous, R.T. 1998. Modelling of instream flow needs: the link between sediment and aquatic habitat. Regulated Rivers: Research \& Management, 14, 79-94.

Miller, S.W., Judson, S., \& Rosenfeld, J. 2014. Responses of macroinvertebrate drift, benthic assemblages, and trout foraging to hydropeaking. Canadian Journal of Fisheries and Aquatic Sciences, 71, 675-687.

Miserendino, M.L. 2009. Effects of flow regulation, basin characteristics and land-use on macroinvertebrate communities in a large arid Patagonian river. Biodiversity and Conservation, 18, 1921-1943.

Monk, W.A., Wood, P.J., Hannah, D.M., \& Wilson, D.A. 2007. Selection of river flow indices for the assessment of hydroecological change. River Research and Applications, 23, 113122.

Monk, W.A., Wood, P.J., Hannah, D.M., Wilson, D.A., Extence, C.A., \& Chadd, R.P. 2006. Flow variability and macroinvertebrate community response within riverine systems. River Research and Applications, 22, 595-615.

Mouthon, J., \& Daufresne, M. 2006. Effects of the 2003 heatwave and climatic warming on mollusc communities of the Saône: a large lowland river and of its two main tributaries (France). Global Change Biology, 12, 441-449.

Moya, N., Gibon, F.-M., Oberdorff, T., Rosales, C., \& Domínguez, E. 2009. Comparación de las comunidades de macroinvertebrados acuáticos en ríos intermitentes y permanentes del altiplano boliviano: implicaciones para el futuro cambio climático. Ecología aplicada, 8, 105-114.

Nouvelot, J.-F., Le Goulven, P., Alemán, M., \& Pourrut, P. 1995. Análisis estadístico y regionalización de las precipitaciones en el Ecuador. El agua en el Ecuador: Clima, precipitaciones, escorrentia. Estudios de Geografia, 7, 27-66.

Olsen, D., Hayes, J., Booker, D., \& Barter, P. 2014. A model incorporating disturbance and recovery processes in benthic invertebrate habitat-flow time series. River Research and Applications, 30, 413-426.

Padrón, R.S. 2013. Análisis de la estructura de la lluvia del páramo. Proyecto de graduación previo a la obtención del grado de Ingeniero Civil, Universidad de Cuenca, Cuenca, Ecuador. $81 \mathrm{pp}$

Poff, N.L., Allan, J.D., Bain, M.B., Karr, J.R., Prestegaard, K.L., Richter, B.D., Sparks, R.E., \& Stromberg, J.C. 1997. The natural flow regime. BioScience, 47, 769-784.

Pringle, C.M. 2001. Hydrologic connectivity and the management of biological reserves: a global perspective. Ecological Applications, 11, 981-998.

Rios-Touma, B., Prat, N., \& Encalada, A.C. 2012. Invertebrate drift and colonization processes in a tropical Andean stream. Aquatic Biology, 14, 233-246.

Ríos $\square$ Touma, B., Encalada, A.C., \& Prat Fornells, N. 2011. Macroinvertebrate Assemblages of an Andean High $\square$ Altitude Tropical Stream: The Importance of Season and Flow. International Review of Hydrobiology, 96, 667-685.

Robinson, C.T. 2012. Long-term changes in community assembly, resistance, and resilience following experimental floods. Ecological Applications, 22, 1949-1961.

Rocha, L., Medeiros, E., \& Andrade, H. 2012. Influence of flow variability on macroinvertebrate assemblages in an intermittent stream of semi-arid Brazil. Journal of Arid Environments, 85, 33-40.

Rolls, R.J., Leigh, C., \& Sheldon, F. 2012. Mechanistic effects of low-flow hydrology on riverine ecosystems: ecological principles and consequences of alteration. Freshwater Science, 31, 1163-1186. 
Snyder, C., \& Johnson, Z. 2006. Macroinvertebrate assemblage recovery following a catastrophic flood and debris flows in an Appalachian mountain stream. Journal of the North American Benthological Society, 25, 825-840.

Stubbington, R., \& Wood, P.J. 2013. Benthic and interstitial habitats of a lentic spring as invertebrate refuges during supra-seasonal drought. Fundamental and Applied Limnology/Archiv für Hydrobiologie, 182, 61-73.

Studholme, A.M., Hampel, H., Finn, D.S., \& Vázquez, R. 2017. Secondary production of caddisflies reflects environmental heterogeneity among tropical Andean streams. Hydrobiologia, 797, 231-246.

Sueyoshi, M., Nakano, D., \& Nakamura, F. 2014. The relative contributions of refugium types to the persistence of benthic invertebrates in a seasonal snowmelt flood. Freshwater Biology, 59, 257-271.

Suren, A., \& Lambert, P. 2010. Temporal variation of invertebrate communities in perennial wetlands. New Zealand Journal of Marine and Freshwater Research, 44, 229-246.

Suren, A.M., \& Jowett, I.G. 2006. Effects of floods versus low flows on invertebrates in a New Zealand gravel $\square$ bed river. Freshwater Biology, 51, 2207-2227.

Tomanová, S. 2007. Functional aspect of macroinvertebrate communities in tropical and temperate running waters. $\mathrm{PhD}$ thesis (in czech), Masaryk University, Brno. pp

Tomanová, S., \& Usseglio-Polatera, P. 2007. Patterns of benthic community traits in neotropical streams: relationship to mesoscale spatial variability. Fundamental and Applied Limnology/Archiv für Hydrobiologie, 170, 243-255.

Townsend, C.R., \& Hildrew, A.G. 1976. Field experiments on the drifting, colonization and continuous redistribution of stream benthos. The Journal of Animal Ecology, 45, 759772.

Vázquez, R., Beven, K., \& Feyen, J. 2009. GLUE based assessment on the overall predictions of a MIKE SHE application. Water resources management, 23, 1325-1349.

Vázquez, R., \& Feyen, J. 2003. Effect of potential evapotranspiration estimates on effective parameters and performance of the MIKE SHE-code applied to a medium-size catchment. Journal of hydrology, 270, 309-327.

Vázquez, R., Willems, P., \& Feyen, J. 2008. Improving the predictions of a MIKE SHE catchment $\square$ scale application by using a multi $\square$ criteria approach. Hydrological Processes, 22, 2159-2179.

Vimos $\square$ Lojano, D., Martínez $\square$ Capel, F., \& Hampel, H. 2017. Riparian and microhabitat factors determine the structure of the EPT community in Andean headwater rivers of Ecuador. Ecohydrology.

Wood, P., Agnew, M., \& Petts, G.E. 2000. Flow variations and macroinvertebrate community responses in a small groundwater $\square$ dominated stream in south $\square$ east England. Hydrological Processes, 14, 3133-3147.

Wood, P., \& Armitage, P. 2004. The response of the macroinvertebrate community to low-flow variability and supra-seasonal drought within a groundwater dominated stream. Archiv für Hydrobiologie, 161, 1-20.

Worrall, T.P., Dunbar, M.J., Extence, C.A., Laize, C.L., Monk, W.A., \& Wood, P.J. 2014. The identification of hydrological indices for the characterization of macroinvertebrate community response to flow regime variability. Hydrological Sciences Journal, 59, 645658.

Wyżga, B., Oglęcki, P., Radecki-Pawlik, A., Skalski, T., \& Zawiejska, J. 2012. Hydromorphological complexity as a driver of the diversity of benthic invertebrate communities in the Czarny Dunajec River, Polish Carpathians. Hydrobiologia, 696, 2946.

Yulianti, J.S., \& Burn, D.H. 1998. Investigating links between climatic warming and low streamflow in the Prairies region of Canada. Canadian Water Resources Journal, 23, 4560. 
(a)

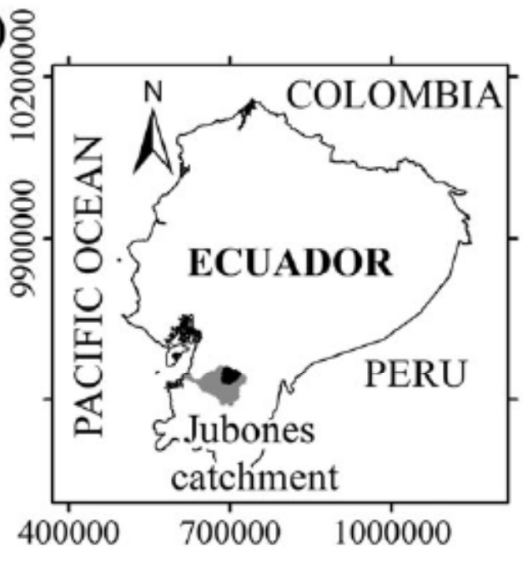

(b) Headwater

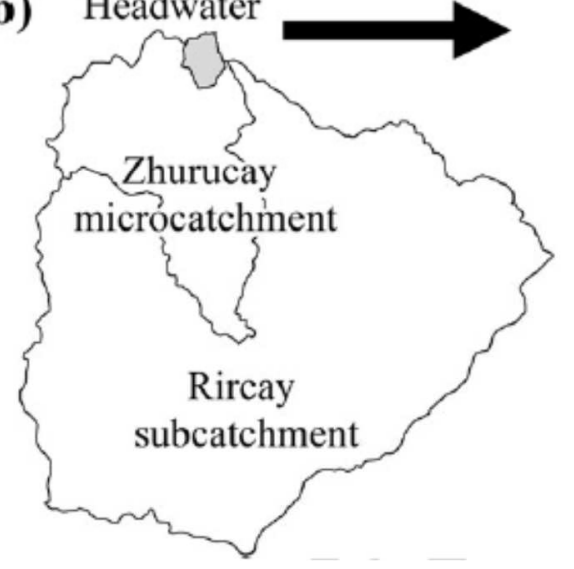

(c)

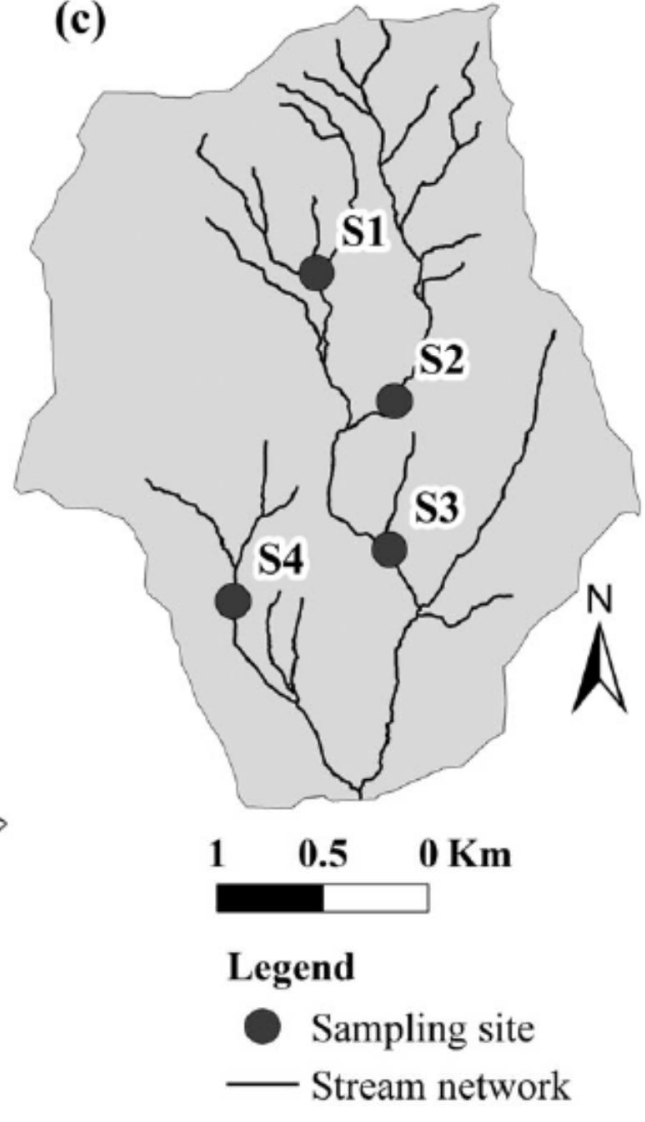

Figure 1. Location of (a) the Jubones river catchment in Ecuador and the Rircay river subcatchment; (b) the study site (Zhurucay microcatchment headwater), located inside the Rircay river subcatchment; and (c) the four sampling points in the study site. 


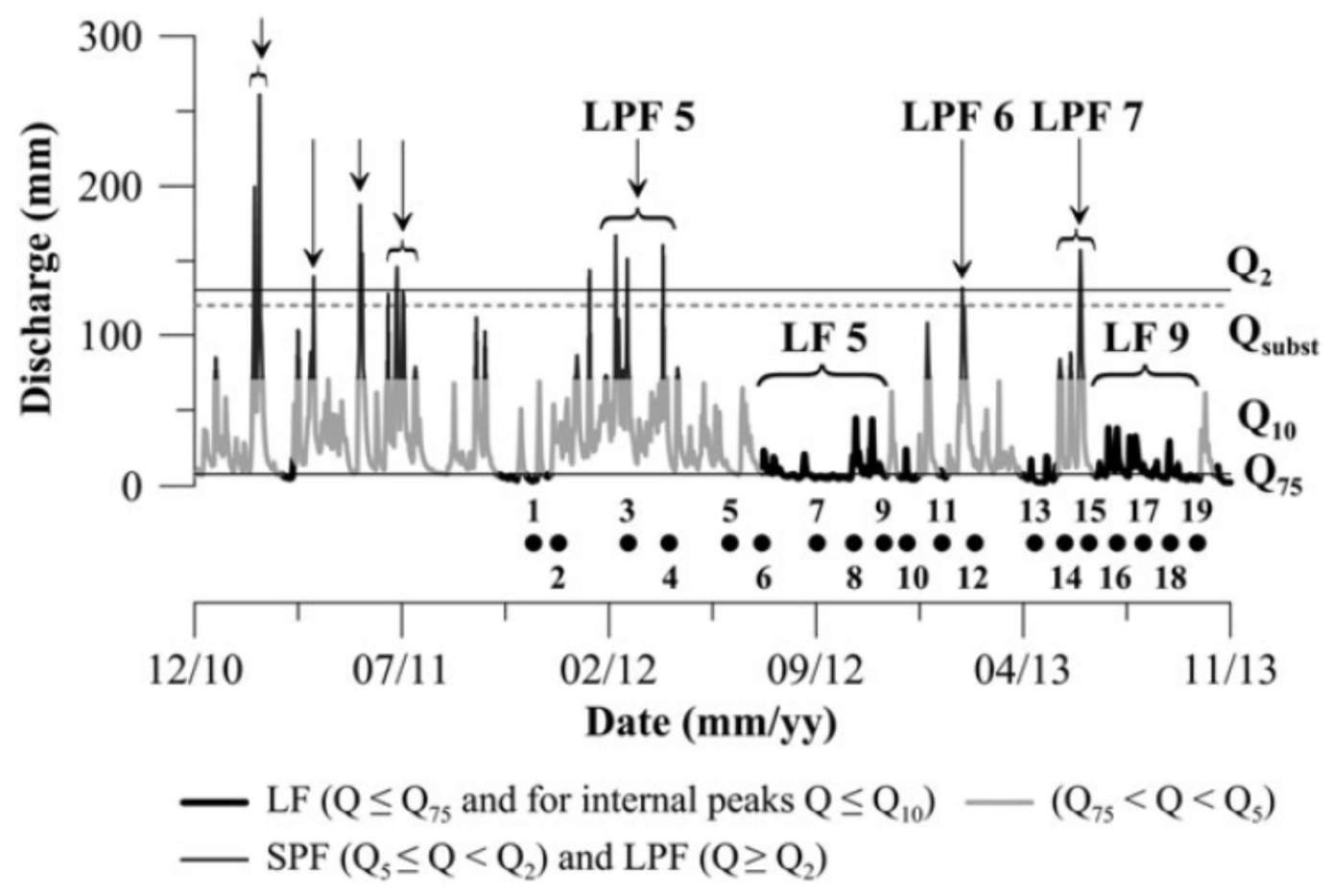

Figure 2. Average daily discharge $\left(\mathrm{Q}_{\text {aver }}\right)$ hydrograph and time evolution of the sampling campaigns (identified by means of dots); Large Peak flow (LPF) events $\left(\mathrm{Q} \geq \mathrm{Q}_{2}\right.$; identified through vertical arrows); and Low flow (LF) events $\left(\mathrm{Q} \leq \mathrm{Q}_{75}\right.$ and for internal pulses $\mathrm{Q} \leq \mathrm{Q}_{10}$; identified through a solid black line in the hydrograph). Q $\mathrm{Qubst}(119.8 \mathrm{~mm})$ is the flow threshold for movement of substrate. Q is the discharge. Discharge thresholds refer to exceedance percentiles. 

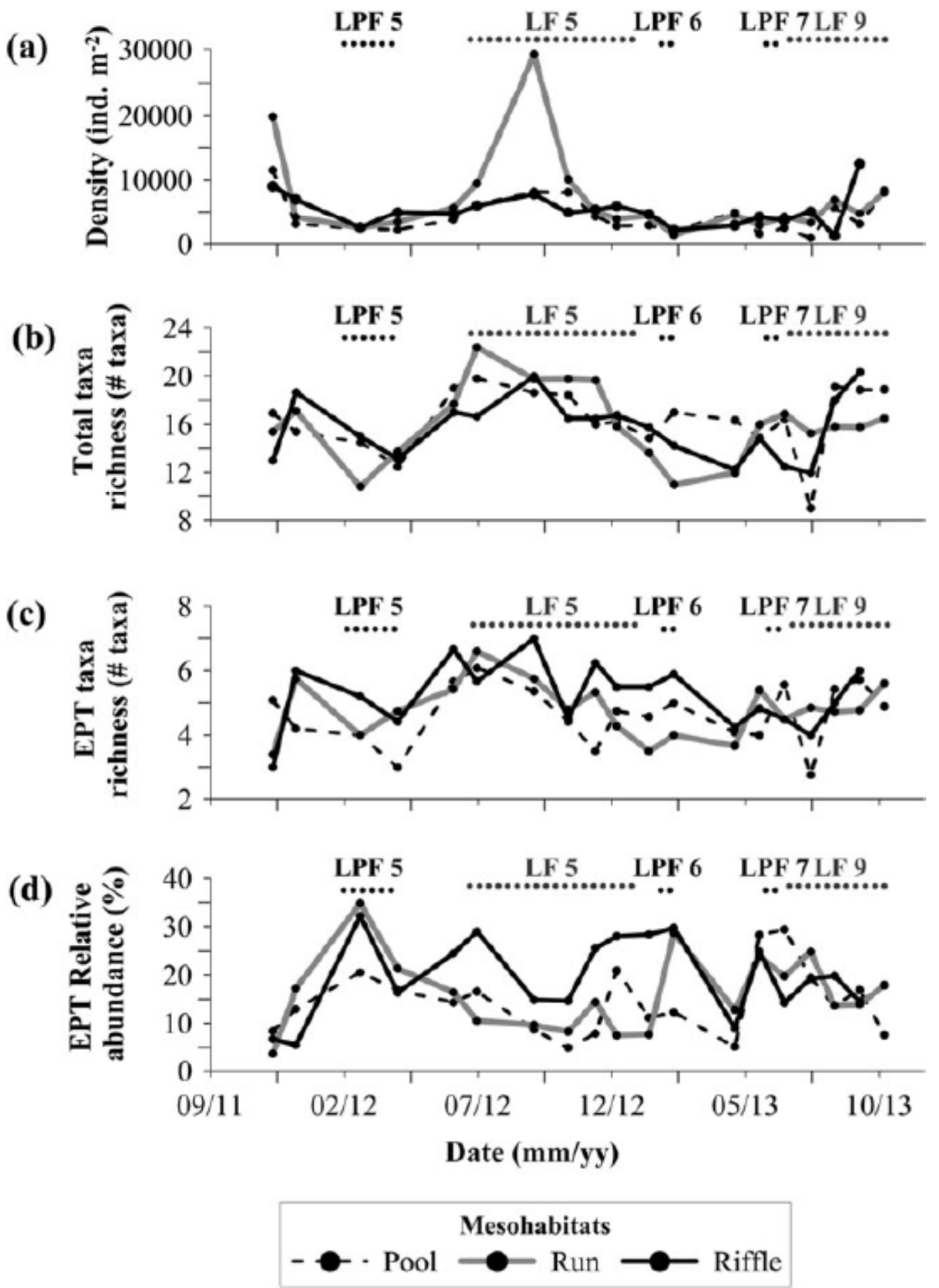

Figure 3. Temporal variation of the average community metrics as a function of the mesohabitat type, namely, (a) density (ind. $\mathrm{m}^{-2}$ ); (b) total taxa richness (\# total); (c) EPT taxa richness (\# total); and (d) EPT relative abundance (\%). 


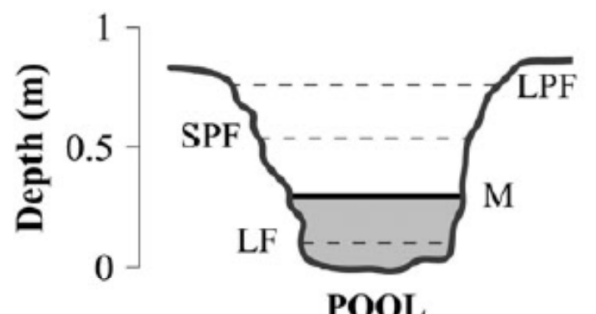

POOL

Fr SS

LPF $=0.864 \quad 109.40$

$\mathrm{SPF}=0.475 \quad 60.16$

$\begin{array}{lll}M & =0.156 & 19.78\end{array}$

LF $=0.054 \quad 6.83$

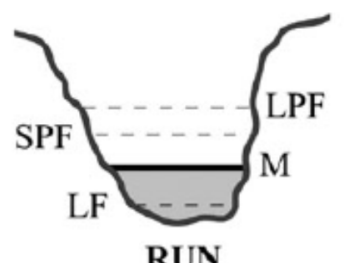

RUN

$\mathrm{Fr}_{\mathrm{r}} \quad \mathrm{SS}$

$\mathrm{LPF}=1.627 \quad 422.89$

SPF $=0.900 \quad 232.53$

$M=0.296 \quad 76.46$

$\mathrm{LF}=0.102 \quad 26.39$

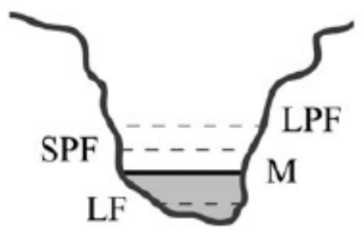

RIFFLE

Fr SS

LPF $=3.048 \quad 1542.79$

$\mathrm{SPF}=1.676 \quad 848.35$

$\begin{array}{lll}M & =0.551 & 278.96\end{array}$

LF $=0.190 \quad 96.27$

Figure 4. Typical cross-sections observed in pool, run, and riffle mesohabitats, showing levels of water surface under different discharge conditions, namely, Large Peak flow (LPF), Small Peak flow (SPF), Low flow (LF) and median (M, observed in the period from 2011 to 2013). Froude number $\left(\mathrm{F}_{\mathrm{r}}\right)$, and shear stress $\left(\mathrm{SS} ; \mathrm{N} \mathrm{m}^{-2}\right)$ values are given for these discharge conditions as a function of the type of mesohabitat. 
Table 1. Description of the hydrological indices calculated from the mean daily discharges ( $\left.Q_{\text {aver }}\right)$. $\mathrm{N}_{\mathrm{i}}$ is the total number of values that a given hydrological index may adopt as a function of the number of days (n) used in its calculation.

\begin{tabular}{|c|c|c|}
\hline Index & $\mathbf{N}_{\mathbf{i}}$ & Description \\
\hline Qsample & 1 & Mean daily discharge recorded on the sampling date. \\
\hline MAXDAYQ(n) & 4 & $\begin{array}{l}\text { Maximum discharge observed in periods of } \mathrm{n}=7,15,30 \text { and } 90 \text { days before } \\
\text { the sampling date. }\end{array}$ \\
\hline COMAXDAY & 1 & Coefficient of variation of the four values of MAXDAYQ(n). \\
\hline FHA & 1 & $\begin{array}{l}\text { Number Large Peak flow pulses observed throughout a one-year period } \\
\text { before each sampling campaign. }\end{array}$ \\
\hline QMAX(k) & 3 & $\begin{array}{l}\text { k-th Large Peak flow pulse occurring immediately before the sampling date, } \\
\text { where } \mathrm{k}=1,2 \text {, and } 3 \text { reflect occurrence in chronological order. }\end{array}$ \\
\hline COQMAX & 1 & Coefficient of variation of the three QMAX values. \\
\hline $\mathrm{FH}(\mathrm{m})$ & 5 & $\begin{array}{l}\text { Number of Large Peak flow and Small Peak flow pulses occurring in the } \\
\text { five periods defined by } m=1,2,3,4 \text {, and } 5 \text { months before the sampling } \\
\text { date. }\end{array}$ \\
\hline MINDAYQ(n) & 4 & $\begin{array}{l}\text { Minimum discharge observed in periods of } \mathrm{n}=7,15,30 \text { and } 90 \text { days before } \\
\text { the sampling date. }\end{array}$ \\
\hline COMINDAY & 1 & Coefficient of variation of the four values of MINDAYQ(n). \\
\hline QMIN & 1 & Low flow pulse occurring immediately before the sampling date. \\
\hline $\mathrm{FL}(\mathrm{m})$ & 5 & $\begin{array}{l}\text { Number of Low flow pulses occurring in the five periods defined by } m=1 \text {, } \\
2,3,4 \text {, and } 5 \text { months before the sampling date. }\end{array}$ \\
\hline
\end{tabular}


Table 2. Beta coefficients $(\beta)$ of the multiple regression analysis using the hydrological indices as independent variables and community metrics and relative abundance of the 10 most abundant taxa as dependent variables, as a function of the mesohabitats. The sample sizes were: $\mathrm{N}=141$ in the pool mesohabitats ( ${ }^{\mathrm{Po}}$ ); $\mathrm{N}=144$ in the run mesohabitats ${ }^{(\mathrm{Ru})}$; and $\mathrm{N}=76$ in the riffle mesohabitats $\left({ }^{\mathrm{Ri}}\right)$. The metrics and taxa that are listed have an associated significance probability $p \leq 0.05$. For the description of the hydrological indices refer to Table 1 .

\begin{tabular}{|c|c|c|c|c|c|c|c|c|c|c|c|c|c|c|c|}
\hline & 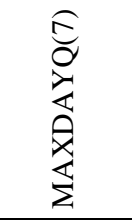 & 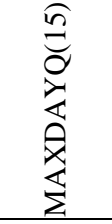 & 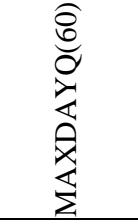 & 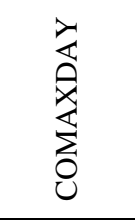 & 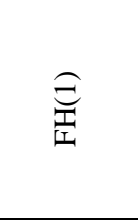 & 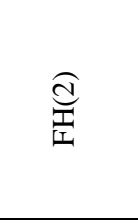 & 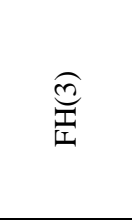 & $\underset{\underset{I}{T}}{\stackrel{\mathbb{T}}{\overparen{T}}}$ & $\underset{I}{\mathbb{I}}$ & 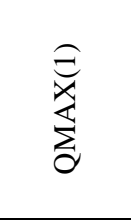 & 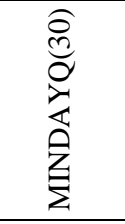 & 突 & 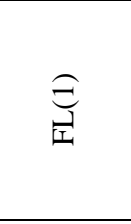 & 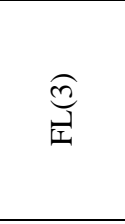 & $\underset{\Xi}{\stackrel{\Xi}{z}}$ \\
\hline \multicolumn{16}{|l|}{ METRICS } \\
\hline Density & $\begin{array}{l}-0.405^{\mathrm{Po}} \\
-0.496^{\mathrm{Ru}}\end{array}$ & & & & & $-0.211^{\mathrm{Ru}}$ & & & & & & & $0.306^{\mathrm{Ru}}$ & & $\begin{array}{c}0.454^{\mathrm{Ru}} \\
-0.377^{\mathrm{Ri}}\end{array}$ \\
\hline $\begin{array}{l}\text { EPT Rel. Abund. } \\
\text { Non-insect Rel. }\end{array}$ & & & & $-0.172^{\mathrm{Po}}$ & & & & & & & $0.178^{\mathrm{Po}}$ & & $-0.287^{\mathrm{Ri}}$ & & \\
\hline Abund. & & & & & $-0.231^{\mathrm{Ru}}$ & $-0.441^{\mathrm{Ru}}$ & & & & $-0.231^{\mathrm{Ri}}$ & & & & & \\
\hline Total taxa richness & & & & & $-0.396^{\mathrm{Po}}$ & $-0.364^{\mathrm{Ri}}$ & & & $0.298^{\mathrm{Ri}}$ & $0.259^{\mathrm{Ru}}$ & & & & $-0.177^{\mathrm{Po}}$ & \\
\hline EPT taxa richness & & & & & $-0.420^{\mathrm{Po}}$ & & & & & $0.181^{\mathrm{Po}}$ & & & & $-0.332^{\mathrm{Po}}$ & \\
\hline Non-insect richness & & & & $-0.290^{\mathrm{Ri}}$ & $-0.240^{\mathrm{Po}}$ & & $-0.589^{\mathrm{Ru}}$ & $-0.301^{\mathrm{Ri}}$ & & $0.190^{\mathrm{Ru}}$ & & & $-0.191^{\mathrm{Ru}}$ & & \\
\hline Evenness & & $0.323^{\mathrm{Po}}$ & & & & & & & & & & $0.342^{\text {Ru }}$ & & & \\
\hline Diversity & & & & $-0.377^{\mathrm{Ri}}$ & & & $-0.441^{\mathrm{Ru}}$ & & & $0.333^{\mathrm{Ru}}$ & & $0.561^{\mathrm{Ru}}$ & & & \\
\hline \multicolumn{16}{|l|}{ TAXA } \\
\hline Chironominae & & & & $-0.217^{\mathrm{Ru}}$ & & & $-0.453^{\mathrm{Ru}}$ & $-0.298^{\mathrm{Ri}}$ & & & & & & & \\
\hline Girardia & & & & & $-0.290^{\mathrm{Ru}}$ & & & & & $-0.180^{\mathrm{Ru}}$ & & & & & \\
\hline Helobdella & & & & $0.226^{\mathrm{Po}}$ & & & & & & & & & & & \\
\hline Hyalella & $0.200^{\mathrm{Po}}$ & & & & & $-0.232^{\mathrm{Ri}}$ & & & & & & & & & \\
\hline Lymnaeidae & & & $-0.255^{\text {Po }}$ & & & & & $-0.250^{\mathrm{Po}}$ & & & & & & & \\
\hline Metrichia* & & & & & $0.257^{\mathrm{Ru}}$ & & & $0.212^{\text {Po }}$ & & & & & $-0.264^{\mathrm{Ri}}$ & & \\
\hline
\end{tabular}


Table 3. Effects of Large Peak (LPFs) and Small Peak flows (SPFs) on community metrics and relative abundance of taxa as a function of the type of mesohabitats according to the statistical test PERMANOVA. The values of the average $(\overline{\mathrm{x}})$, standard deviation (SD), and F statistic (F) of the metrics and taxa are listed with the associated significance probability $p \leq 0.05$. Froude number $\left(\mathrm{F}_{\mathrm{r}}\right)$ and shear stress $\left(\mathrm{SS}, \mathrm{N} \mathrm{m}^{-2}\right)$ estimates for each mesohabitat type and peak flow event are also included.

\begin{tabular}{|c|c|c|c|c|c|c|}
\hline $\begin{array}{c}\text { Mesohabitat } \\
\text { Type }\end{array}$ & Event characteristics & $\begin{array}{l}\text { Community } \\
\text { metric/taxa }\end{array}$ & $\overline{\mathbf{x}}$ & SD & $\mathbf{F}$ & $\mathbf{P}$ \\
\hline \multirow{6}{*}{ POOL } & LPF 5 (160.4 mm) & Density & $-3,972$ & 1609 & 5.49 & 0.040 \\
\hline & $\mathrm{Fr}=1.07 ; \mathrm{SS}=135.0$ & Evenness & 0.13 & 0.02 & 12.07 & 0.020 \\
\hline & & Total taxa richness & -5.3 & 3.45 & 5.24 & 0.050 \\
\hline & LPF 7 (157.2 mm) & EPT Rel. Abund. & 20.2 & 11.85 & 7.68 & 0.026 \\
\hline & $\mathrm{Fr}=1.04 ; \mathrm{SS}=132.3$ & Hydrachnidia & 4.2 & 2.74 & 7.86 & 0.022 \\
\hline & $\begin{array}{l}\text { SPF }(108.0 \mathrm{~mm}) \\
\operatorname{Fr}=0.72 ; \mathrm{SS}=90.9\end{array}$ & Oligochaeta & -1.2 & 0.42 & 8.02 & 0.030 \\
\hline \multirow{12}{*}{ RUN } & LPF 5 (160.4 mm) & Density & $-6,602$ & 3,260 & 7.93 & 0.000 \\
\hline & $\mathrm{Fr}=2.02 ; \mathrm{SS}=521.7$ & Total taxa richness & -5.6 & 2.04 & 11.84 & 0.000 \\
\hline & & EPT Rel. Abund. & 20.5 & 4.79 & 4.77 & 0.020 \\
\hline & & Metrichia* & 7.5 & 3.9 & 3.82 & 0.030 \\
\hline & & Girardia & -16.1 & 5.91 & 6.53 & 0.010 \\
\hline & & Chironominae & -9.2 & 3.71 & 16.69 & 0.000 \\
\hline & & Oligochaeta & -2.9 & 1.85 & 4.21 & 0.020 \\
\hline & LPF 6 (131.7 mm) & EPT Rel. Abund. & 15.1 & 3.34 & 8.03 & 0.020 \\
\hline & $\mathrm{Fr}=1.66 ; \mathrm{SS}=428.4$ & Oligochaeta & 7.9 & 4.73 & 2.74 & 0.050 \\
\hline & SPF $(108.0 \mathrm{~mm})$ & Evenness & -0.1 & 0.02 & 8.83 & 0.020 \\
\hline & $\mathrm{Fr}=1.36 ; \mathrm{SS}=351.3$ & Diversity & -0.4 & 0.13 & 7.69 & 0.020 \\
\hline & & Helobdella & -0.6 & 0.2 & 3.88 & 0.040 \\
\hline \multirow{8}{*}{ RIFFLE } & LPF $5(160.4 \mathrm{~mm})$ & Density & $-5,022$ & 1,866 & 4.57 & 0.010 \\
\hline & $\mathrm{Fr}=3.76 ; \mathrm{SS}=1,903.4$ & EPT Rel. Abund. & 26.0 & 8.06 & 4.52 & 0.030 \\
\hline & & Girardia & -21.1 & 11.32 & 4.33 & 0.040 \\
\hline & LPF 6 (131.7 mm) & Density & $-2,560$ & 583 & 6.63 & 0.010 \\
\hline & $\mathrm{Fr}=3.09 ; \mathrm{SS}=1,562.8$ & Evenness & 0.13 & 0.04 & 5.77 & 0.050 \\
\hline & & Chironominae & -6.3 & 4.15 & 15.73 & 0.010 \\
\hline & LPF $7(157.2 \mathrm{~mm})$ & Hydrachnidia & 3.9 & 3.02 & 4.92 & 0.030 \\
\hline & $\mathrm{Fr}=3.69 ; \mathrm{SS}=1,865.4$ & Contulma & 6.4 & 6.81 & 2.46 & 0.031 \\
\hline
\end{tabular}

* Taxonomic groups belonging to the EPT orders. 
Table 4. Effects of duration (n, in days) of Low flow on community metrics and relative abundance of taxa as a function of the type of mesohabitat according to the statistical test PERMANOVA. The values of the average $(\overline{\mathrm{X}})$, standard deviation $(\mathrm{SD})$, and $\mathrm{F}$ statistic $(\mathrm{F})$ of the metrics and, in the case of taxa, the differences in relative abundances between two compared campaigns, are listed with an associated significance probability $p \leq 0.05$.

\begin{tabular}{|c|c|c|c|c|c|c|}
\hline $\begin{array}{c}\text { Mesohabitat } \\
\text { Type }\end{array}$ & $\mathbf{n}$ & $\begin{array}{l}\text { Community } \\
\text { metric/taxa }\end{array}$ & $\bar{x}$ & SD & $\mathbf{F}$ & $p$ \\
\hline \multirow{14}{*}{ POOL } & 90 & Density & $3,515.4$ & 749.2 & 5.10 & 0.030 \\
\hline & 115 & & $6,393.3$ & $1,543.3$ & 11.44 & 0.030 \\
\hline & 60 & Evenness & -0.1 & 0.04 & 6.95 & 0.020 \\
\hline & 90 & & -0.2 & 0.06 & 17.52 & 0.030 \\
\hline & 10 & Total taxa richness & -3.5 & 1.12 & 6.12 & 0.020 \\
\hline & 30 & & 11.8 & 3.71 & 8.18 & 0.030 \\
\hline & 90 & Diversity & -0.4 & 0.09 & 8.74 & 0.010 \\
\hline & 30 & EPT Rel. Abund. & -12.7 & 2.78 & 15.96 & 0.030 \\
\hline & 10 & EPT taxa richness & -2.7 & 0.33 & 7.07 & 0.020 \\
\hline & 115 & & -1.0 & 0.71 & 6.01 & 0.050 \\
\hline & 30 & Hydrachnidia & -5.2 & 5.85 & 4.50 & 0.030 \\
\hline & 30 & Psychoda & -4.7 & 6.74 & 4.35 & 0.030 \\
\hline & 115 & & 1.6 & 1.21 & 2.77 & 0.040 \\
\hline & 75 & Claudioperla* & -1.3 & 0.51 & 3.87 & 0.030 \\
\hline \multirow{4}{*}{ RUN } & 75 & Density & $-21,997.8$ & $11,671.41$ & 9.42 & 0.030 \\
\hline & 115 & & $-7,403.3$ & $3,228.87$ & 14.37 & 0.000 \\
\hline & 115 & Total taxa richness & -2.8 & 1.19 & 7.75 & 0.030 \\
\hline & 115 & Orthocladiinae & 8.6 & 6.49 & 5.27 & 0.030 \\
\hline
\end{tabular}

* Taxonomic groups belonging to the EPT orders. 


\section{ANNEXES}

Annex A. Main physical characteristics of the four studied streams (S1, S2, S3 and S4).

Annex B. Presence of taxa as a function of the studied mesohabitats and streams (S1, S2, S3 and S4).

Annex C. Beta coefficients ( $\beta$ ) of the multiple regression analysis using the hydrological indices as independent variables and the community metrics as dependent variables, as a function of the mesohabitats. The sample sizes were: $\mathrm{N}=141$ in the pool mesohabitats; $\mathrm{N}=144$ in the run mesohabitats; and $\mathrm{N}=76$ in the riffle mesohabitats. The metrics that are listed have an associated significance probability $p \leq 0.05$.

Annex D. Beta coefficients ( $\beta$ ) of the multiple regression analysis using the hydrological indices as independent variables and the relative abundance of the 10 most dominant macroinvertebrate taxa as dependent variables, as a function of the mesohabitats. The sample sizes were: $N=141$ in the pool mesohabitats; $\mathrm{N}=144$ in the run mesohabitats; and $\mathrm{N}=76$ in the riffle mesohabitats. The taxa that are listed have an associated significance probability $p \leq 0.05$. 